\title{
Experiência Psicológica de Inclusão entre Estagiárias de Psicologia em Equipes Multiprofissionais
}

\author{
Fabíola Marinho Costa ${ }^{1}$ \\ Roberval Passos de Oliveira ${ }^{1}$ \\ ${ }^{1}$ Universidade Federal do Recôncavo da Bahia, BA, Brasil. ${ }^{1}$ Universidade Federal do Recôncavo da Bahia, BA, Brasil. \\ Antonio Virgílio Bittencourt Bastos ${ }^{2}$ \\ ${ }^{2}$ Universidade Federal da Bahia, BA, Brasil.
}

Resumo: O estágio é um espaço de vivências de integração ensino-trabalho, que pode viabilizar a concretização de conhecimentos em ações profissionais e possibilitar ao estudante trabalhar com pessoas de diferentes identidades. Diante dessa diversidade, a experiência de inclusão no trabalho se relaciona com a percepção dos indivíduos quanto a sua aceitação, respeito e valorização, em função de sua identidade individual e grupal. Nesse sentido, este estudo objetivou compreender a experiência psicológica de inclusão entre estagiárias de Psicologia. Utilizou-se uma abordagem qualitativa, por meio da realização de entrevistas narrativas com 15 estudantes de Psicologia que estagiavam em equipes multiprofissionais de saúde, com idades entre 23 e 57 anos; dentre eles, 14 eram mulheres e 10 eram autodeclaradas negras. Mediante o uso de categorias temáticas, as narrativas foram analisadas, buscando compreender os sentidos que as experiências tiveram para as entrevistadas. A experiência psicológica de inclusão foi vinculada à percepção de pertencimento à equipe e de acesso às informações e aos recursos necessários para o desenvolvimento do trabalho. Por outro lado, as estagiárias expressaram que, em algumas situações, não sentiam interação e comunicação construtivas com médicos e trabalhadores da enfermagem. Os resultados afirmaram a importância dos estágios curriculares como dispositivos de inclusão no mundo do trabalho, reiterando que a diversidade abrange elementos como experiência no trabalho e categoria profissional. Entende-se que esses conhecimentos podem promover importantes discussões e, assim, fundamentar a elaboração de políticas e práticas organizacionais mais inclusivas para lidar com uma força de trabalho diversa.

Palavras-chave: Inclusão no trabalho, Diversidade no trabalho, Equipes multiprofissionais, Psicologia, Estágios.

\section{Psychologic Experience of Inclusion between Psychology Interns in Multiprofessional Teams}

\begin{abstract}
The internship is a space for teaching-work integration experiences, which can enable knowledge to materialize in professional actions and enable the student to work with people of different identities. Given this diversity, the experience of inclusion at work relates to the perception of individuals regarding their acceptance, respect, and appreciation, according to their individual and group identity. In this sense, our study aimed to understand the psychological experience of inclusion among psychology interns. A qualitative approach was used, with narrative interviews with 15 Psychology students interning with multiprofessional health teams, aged between 23 and 57 years old; among them, 14 women and 10 self-declared black. By using thematic categories, we analyzed the narratives, seeking to understand the meanings that the experiences had for the interviewees. The psychological experience of inclusion was linked to the perception of belonging to the team and of access to the information and resources necessary for the development of the
\end{abstract}


work. On the other hand, the interns expressed that, in some situations, they felt no constructive interaction and communication with nursing workers and doctors. The results affirmed the importance of curricular internships as devices for inclusion in the world of work, reiterating that diversity includes elements such as work experience and professional category. We understand that this knowledge can promote important discussions and, thus, support the development of more inclusive organizational policies and practices to deal with a diverse workforce.

Keywords: Inclusion at work, Diversity at work, Multiprofessional teams, Psychology, Internship.

\title{
Experiencia Psicológica de Inclusión entre Pasantes de Psicología en Equipos Multiprofesionales
}

\begin{abstract}
Resumen: La pasantía es un espacio para experiencias de integración trabajo-enseñanza, que puede permitir la concreción del conocimiento en acciones profesionales y que el alumno trabaje con personas de diferentes identidades. En vista de esta diversidad, la experiencia de inclusión en el trabajo está relacionada con la percepción de los individuos con respecto a su aceptación, respeto y apreciación, de acuerdo con su identidad individual y grupal. En este sentido, este estudio tuvo como objetivo comprender la experiencia psicológica de inclusión entre las pasantes de Psicología. Se utilizó el enfoque cualitativo, realizando entrevistas narrativas con 15 estudiantes de psicología, que eran pasantes en equipos de salud multiprofesionales, con edades entre 23 y 57 años, de las cuales 14 eran mujeres y 10 autodeclararon negras. Mediante el uso de categorías temáticas, se analizaron las narrativas, buscando comprender los significados que las experiencias tuvieron para las entrevistadas. La experiencia psicológica de inclusión estuvo vinculada a la percepción de pertenencia al equipo y al acceso a la información y los recursos necesarios para el desarrollo del trabajo. Por otro lado, las pasantes expresaron que, en algunas situaciones, no sentían una interacción constructiva y comunicación con los trabajadores de enfermería y los médicos. Los resultados afirmaron la importancia de las pasantías curriculares como dispositivos para la inclusión en el mundo laboral, reiterando que la diversidad incluye elementos como la experiencia laboral y la categoría profesional. Se entiende que este conocimiento puede promover debates importantes y, por lo tanto, apoyar el desarrollo de políticas y prácticas organizacionales más inclusivas para tratarse con una fuerza laboral diversa.
\end{abstract}

Palabras clave: Inclusión en el trabajo, Diversidad en el trabajo, Equipos multiprofesionales, Psicología, Pasantía.

\section{Introdução}

O estágio configura-se como um momento de transição da vida acadêmica para o mundo do trabalho, no qual estudantes têm a oportunidade de utilizar o conhecimento produzido ao longo do curso para realização de atividades em contextos profissionais e reconhecer potencialidades e limitações da práxis de uma profissão (Oliveira et al., 2019). No caso da formação em saúde, o estágio também é o momento de ter contato com outros trabalhadores e com usuários dos serviços de saúde. Nesse sentido, o estágio é entendido como um espaço de vivências de integração ensino-trabalho. Ao considerar essas vivências, o presente estudo enfoca a experiência psicológica de inclusão entre estudantes de Psicologia, cujos estágios curriculares foram realizados em equipes multiprofissionais de saúde, que são grupos constituídos pela diversidade na formação educacional e na experiência funcional, entre outras características.

O termo diversidade é comumente utilizado para reconhecer grupos que são marginalizados com base em sua identidade social (por exemplo, raça, gênero, etnia, religião, deficiência, idade, orientação sexual), embora a diversidade envolva uma matriz de 
atributos e características diferentes, pois se refere às variáveis formas pelas quais as pessoas diferem (Byrd, 2014). Cada variável deve ser tratada como uma construção teórica distinta, visto que os efeitos de uma variável não serão necessariamente os mesmos de outras características. Além disso, as pessoas não têm uma única característica demográfica e as interações entre as diferentes características são complexas.

Diante disso, a diversidade tem sido investigada de diversas maneiras, em termos de características visíveis versus menos visíveis (ou invisíveis) e variações culturais (Ferdman, Avigdor, Braun, Konkin, \& Kuzmycz, 2010), que podem ser classificadas de acordo com a seguinte tipologia (Van Knippenberg \& Schippers, 2007): a) atributos demográficos prontamente observáveis (por exemplo, sexo, raça/etnia, idade); b) atributos relacionados ao trabalho, como diferenças funcionais ou na educação; e c) atributos que não são facilmente visíveis e nem sempre relacionadas ao trabalho, como diferenças de personalidade, atitudes e valores. Embora a diversidade possa dizer respeito a qualquer dimensão possível da diferenciação, as pesquisas sobre diversidade no trabalho têm focado diferenças relacionadas a atributos como gênero, idade, etnia, formação educacional e experiência funcional (Van Knippenberg \& Schippers, 2007).

Existem várias possibilidades para construção de identidade disponíveis para os indivíduos se identificarem ou serem categorizados - por exemplo, gênero, ocupação - e essas múltiplas identidades impactam simultaneamente as impressões pessoais acerca dos outros e as próprias experiências de identidade, moldando percepções, experiências e interações de maneiras fundamentais (Kang \& Bodenhausen, 2015). As diferentes formas de compreensão da realidade, seus valores e suas crenças influenciam o contexto, as relações nas organizações e as experiências individuais ali vivenciadas (Torres, França, Oliveira, \& Presotti, 2016).

Estudos sobre diversidade em contextos de trabalho tendem a se concentrar nas interações interpessoais e nos processos intergrupais, que envolvem pessoas de diferentes identidades trabalhando juntas em uma equipe ou organização (Ferdman \& Sagiv, 2012). Essas interações e processos dependem profundamente das identidades que são percebidas nos outros e daquelas que atribuímos a nós mesmos (Kang \& Bodenhausen, 2015). Por isso, a dinâmica do poder e privilégios baseados em grupo - incluindo sistemas de dominação, subordinação e opressão (por exemplo, racismo, sexismo, heterossexismo) - é bastante enfatizada entre os especialistas em diversidade (Ferdman \& Sagiv, 2012). Pessoas pertencentes a grupos tradicionalmente sub-representados nas organizações, em termos de poder, prestígio e status, podem ser consideradas "diversas" ou "minorias" (Hanashiro, Torres, Ferdman, \& D’Amario, 2011).

O campo da diversidade nas organizações é bastante amplo e incorpora várias perspectivas. Entretanto, no geral, esse campo enfatiza a compreensão e a intervenção em grupos e locais de trabalho heterogêneos para reduzir ou eliminar o preconceito e a discriminação e se beneficiar de diferenças para maximizar a inclusão e as contribuições dos indivíduos, aumentar a justiça social e a equidade e proporcionar maior sucesso organizacional (Ferdman \& Sagiv, 2012). Os estudos nas organizações, realizados em contexto brasileiro, ainda têm dado pouca ênfase à diversidade, às especificidades do contexto organizacional brasileiro diante dessa diversidade e à efetividade das políticas de promoção da diversidade nas organizações brasileiras (Rosa, 2014).

Diversidade em um grupo, que se refere à quantidade de heterogeneidade presente, não garante que a inclusão também exista (Ferdman et al., 2010). Mais recentemente, o campo da diversidade nas organizações tem voltado sua atenção à inclusão, que vai muito além da compreensão e do benefício da diversidade e incorpora a atenção às experiências de se sentir engajado, envolvido, seguro, valorizado e autêntico, tanto no nível individual quanto no grupo (Ferdman \& Sagiv, 2012).

Para entender e se beneficiar da diversidade, estudiosos consideram a inclusão e sua prática como uma abordagem fundamental (Ferdman \& Deane, 2014). Comparado ao conceito de diversidade, o conceito de inclusão apresenta um menor desenvolvimento no campo dos estudos organizacionais, especialmente quanto a sua operacionalização (Hanashiro et al., 2011). Nesse campo, a inclusão é investigada por meio de diferentes terminologias, enfocando, por vezes, aspectos mais objetivos ou mais subjetivos, o que se constitui como um desafio para sua delimitação conceitual (Torres et al., 2016). Bernardo Ferdman e seus colaboradores têm se destacado na proposição de definições assim como na criação de escalas para a mensuração desse fenômeno, que também tem sido discutido em estudos brasileiros como D'Amario (2009), Torres \& Pérez-Nebra (2014), Hanashiro et al. (2016), Torres et al. (2016). Diante disso, o presente 
estudo abordará o tema da inclusão em contextos de trabalho a partir dessa perspectiva.

A inclusão é um processo ativo, no qual indivíduos, grupos, organizações e sociedades - em vez de buscar a homogeneidade - veem e abordam a diversidade como um recurso valorizado (Ferdman, 2017). Em um sistema inclusivo, valorizamos a nós mesmos e aos outros por causa e não apesar de nossas diferenças (ou semelhanças); todos - por meio de múltiplos tipos de diferenças - devem ser considerados como participantes e colaboradores que sentem e estão conectados ao coletivo maior, sem terem que abrir mão da singularidade individual, das identidades estimadas ou das qualidades vitais (Ferdman, 2014).

A inclusão envolve experimentar um senso de conexão e participação combinada com um sentido, aparentemente contraditório, de diferença e singularidade. Essa tensão pode ser aumentada quando existem padrões de desigualdade histórica ou estigmas baseados em grupos (Ferdman, 2017). Os diferentes grupos de identidade não têm o mesmo status nas sociedades - alguns tendem a ser sistematicamente privilegiados, enquanto outros são sistematicamente desfavorecidos. Quando os grupos buscam justiça social, estão lutando para viverem livres e sem preconceitos. No entanto, isso pode levar outros grupos hegemônicos-e, portanto, mais confortáveis - a terem uma sensação de perda (e até de ataque) e a responderem com demandas paralelas ou a procurarem suprimir ou minimizar as demandas do grupo que está em busca de mudanças e direitos (Ferdman, 2017).

A sociedade está se tornando mais heterogênea em diferentes dimensões, desde as mais visíveis até as menos observáveis, e esse atributo gera uma vantagem competitiva, desde que as pessoas, mais do que inseridas, sintam-se incluídas de forma a usarem seu potencial sem as barreiras (in)visíveis do ambiente organizacional (Hanashiro et al., 2011). Trabalhadores que vivenciam práticas de gestão relacionadas à diversidade e inclusão precisam estar preparados para lidar com visões opostas não como resistência, mas como manifestações variáveis e normais da dinâmica da diversidade nas organizações e sociedades e da própria prática da inclusão (Ferdman, 2017). A inclusão é um processo que envolve relacionamentos humanos e a experiência subsequente daqueles que participam desses relacionamentos. Assim, embora a inclusão seja mais interessante no contexto da diversidade, é um processo que pode ser distinto do grau de diversidade de um grupo (Ferdman et al., 2010).

A inclusão é complexa e multifacetada, mas, ao mesmo tempo, pode ser simples e direta: trata-se de presença, participação, segurança, voz, autenticidade, equidade e igualdade para mais pessoas em suas identidades (Ferdman, 2017). O núcleo da inclusão é como as pessoas a experimentam, a experiência psicológica, que opera no nível individual e, muitas vezes, também coletivamente (Ferdman, 2014). Investigações sobre essa experiência tipicamente focalizaram esse construto no nível individual. Embora a inclusão tenha alguns efeitos demonstrados nesse nível, seu impacto total ocorre no nível do grupo; consequentemente, é mais provável que grupos que a experimentam mais, apresentem-na enquanto característica cultural do grupo como um todo e não uma perspectiva idiossincrática dos membros individualmente (Ferdman et al., 2010).

No presente estudo, a inclusão será estudada em um nível mais micro, enfatizando a experiência psicológica da inclusão - a crença das pessoas (estagiárias de Psicologia) de que elas podem se sentir seguras, ouvidas, envolvidas, presentes, autênticas, valorizadas e respeitadas, tanto como indivíduos, quanto como membros de múltiplos grupos de identidade (mais especificamente como representantes da Psicologia).

Nessa perspectiva, a inclusão se relaciona a como a pessoa percebe que está sendo tratada na e pela organização, em função de características relativas a grupos aos quais pertence; assim, o que importa é o efeito do tratamento, a percepção, e não a intenção. Considerando a inclusão um fenômeno multifacetado, Ferdman, Barrera, Allen e Vuong (2009) distinguem dois conceitos: comportamento inclusivo e experiência psicológica de inclusão. Os comportamentos inclusivos são ações individuais e grupais resultantes ou provocadoras de políticas e procedimentos organizacionais, que promovem um clima inclusivo e são adotadas pelo indivíduo, pelos membros do grupo de trabalho e pela organização; são descritos por meio de seis componentes: criar ambiente de segurança; reconhecer os outros; lidar com conflitos e diferenças; ser capaz e ter vontade de aprender; usar e dar voz; reforçar a representação. Já a experiência psicológica de inclusão é a percepção dos indivíduos quanto a sua aceitação, respeito e valorização, do ponto de vista de sua identidade individual e grupal, e consiste no senso psicológico individual de que a pessoa 
está sendo, de fato, incluída. Esse conceito teórico é composto por cinco componentes: sentimento de valorização; autenticidade; reconhecimento da diversidade; envolvimento e engajamento no grupo de trabalho; influência na tomada de decisão. Há uma forte associação entre os dois constructos, de modo que o comportamento inclusivo prediz a experiência de inclusão: ações inclusivas, por parte dos atores organizacionais, podem proporcionar o sentimento de que se é incluído (Ferdman et al., 2009).

Ademais, muitas sociedades assumiram que os recém-chegados, se forem permitidos, devem ser totalmente assimilados à sociedade receptora. Essa também tem sido uma premissa típica em muitas organizações: cabe aos recém-chegados se adaptarem ao modo como as coisas já são feitas na organização. Isso é percebido se esses recém-chegados divergirem do modo de funcionamento da organização, especialmente em termos de padrões culturais, identidades visíveis e poder (Ferdman, 2017).

Nesse sentido, o presente estudo tem como objetivo compreender a experiência psicológica de inclusão entre estagiárias de Psicologia (recém-chegadas aos contextos de trabalho) durante vivências de integração ensino-trabalho. Ao investigar essas estudantes, abordou-se os atributos "formação educacional" e "experiência funcional", assim como as interações interpessoais e os processos intergrupais que envolvem as estagiárias ao trabalhar em equipes multiprofissionais de saúde. Entende-se que o crescimento do conhecimento referente à inclusão no ambiente organizacional - que difere dos estudos sobre inclusão social, recorrentes na literatura - possibilita uma maior compreensão do processo de inclusão nas organizações e de suas ações, ao mesmo tempo em que visa que as pessoas possam sentir-se psicologicamente incluídas, o que acarreta ganhos para os trabalhadores e para a organização (Hanashiro et al., 2011).

\section{Método}

O presente estudo fez uso de uma abordagem qualitativa, buscando estabelecer diálogos entre os discursos de estagiárias de Psicologia e a produção teórica sobre diversidade e inclusão. As participantes da pesquisa foram selecionadas dentre estagiárias do curso de Psicologia de uma universidade pública do estado da Bahia, que estavam realizando estágio curricular, em contextos de trabalho envolvendo equipes multiprofissionais de saúde. As estudantes estagiavam em um destes sete contextos: três hospitais, três serviços de atenção à saúde mental - Centros de Atenção Psicossocial (Caps) e serviço vinculado à universidade - e um programa social.

Participaram do estudo 15 estudantes de Psicologia, com idades entre 23 e 57 anos, dos quais 14 eram mulheres, 10, autodeclaradas negras (pretas ou pardas), três eram autodeclaradas brancas e uma não se posicionou em relação à cor. $\mathrm{O}$ único participante homem se autodeclarou branco. Considerando o número de mulheres e em atenção às reflexões relacionadas à diversidade e inclusão, será utilizado o gênero feminino para se referir às pessoas que participaram da pesquisa. O critério para a definição do número de participantes foi a saturação dos dados coletados.

A pesquisa envolveu a realização de entrevistas narrativas, orientadas por um roteiro semiestruturado que abordava temas relacionados a: características dos estágios; atividades desenvolvidas; interações com colegas, orientadores, trabalhadores de saúde, usuários dos serviços; vivências de situações de inclusão/exclusão no contexto dos estágios. Mediante a elaboração de narrativas, as pessoas lembram o que aconteceu, colocam a experiência em uma sequência coerente e significativa, encontram possíveis explicações para isso e jogam com a cadeia de acontecimentos que constroem a vida (Jovchelovitch \& Bauer, 2015). As estagiárias foram contatadas, informadas sobre os objetivos do estudo e convidadas a participar da pesquisa por meio da narração de suas histórias relativas ao trabalho desenvolvido no estágio, tendo como um dos focos o processo de inclusão. Durante a realização do estudo foram tomadas todas as providências necessárias para garantir a integridade ética das estagiárias e o projeto de pesquisa foi aprovado por um Comitê de Ética em Pesquisa. Na apresentação dos resultados do estudo, foram utilizados nomes fictícios para preservar a identidade das participantes da pesquisa.

As entrevistas, realizadas entre maio e junho de 2019, foram registradas em gravador digital de voz e, posteriormente, realizou-se transcrição verbatim e digitação em computador. A partir da leitura das narrativas produzidas pelas estagiárias, esses relatos foram categorizados mediante o uso de categorias temáticas relacionadas à experiência psicológica de inclusão (envolvimento e engajamento no grupo de trabalho; influência na tomada de decisão; reconhecimento da diversidade; sentimento de valorização; 
autenticidade) e a comportamentos inclusivos (usar e dar voz; reconhecer os outros), de acordo com a proposição teórica de Ferdman et al. (2009). Além disso, o processo de inclusão foi analisado em diferentes níveis de análise (individual; intragrupal; intergrupal; organizacional). As narrativas foram analisadas conforme proposta de Gibbs (2009), buscando compreender os sentidos que as experiências tiveram para as entrevistadas.

\section{Resultados e discussão}

Os resultados serão apresentados por meio das categorias temáticas definidas no estudo. Inicialmente serão problematizadas as questões relacionadas à experiência psicológica de inclusão, explorando seus componentes. A seguir, serão abordados os comportamentos inclusivos apresentados pelas estagiárias. Por fim, discutir-se-á a inclusão no trabalho em diferentes níveis de análise.

\section{Componentes da experiência psicológica de inclusão}

A experiência psicológica de inclusão das estagiárias foi especialmente vinculada ao envolvimento e engajamento no grupo de trabalho. Esse componente pode ser definido como sentimento de pertencimento, percepção de participação no grupo de trabalho e de acesso às informações e recursos necessários para o desenvolvimento das atividades de trabalho (Ferdman et al., 2009). As estagiárias relataram como foram se engajando no grupo de trabalho, destacando a inclusão como um processo. A inclusão trata do quanto as organizações e seus membros se conectam e se engajam, considerando vários processos ao longo do tempo, que envolvem padrões de comportamento e experiências no contexto das relações entre indivíduos, entre pessoas e seus grupos e organizações e entre grupos (Ferdman, 2014). Nessa perspectiva, o tempo, no contexto de trabalho, é um importante fator a ser considerado na análise da experiência psicológica de inclusão.

Além do envolvimento e engajamento com o grupo de trabalho, a autenticidade também foi relacionada ao tempo que as estagiárias tinham no estágio. A autenticidade é um componente da experiência psicológica que diz respeito ao sentimento de que há liberdade de expressão, de que é possível conversar honestamente com outros colegas e ser espontânea no ambiente de trabalho, sentindo-se livre para se afastar das normas do grupo (Ferdman et al., 2009). O envolvimento e a autenticidade seriam mais sentidos ao longo do estágio, embora o estágio seja temporário e de curta duração, o que não facilitaria que a estagiária desenvolvesse uma maior espontaneidade no ambiente de trabalho.

Ter acesso às informações e aos recursos necessários para a execução do trabalho também foi relatado como algo relacionado à experiência psicológica de inclusão das estagiárias. A acessibilidade ao espaço no estágio já foi citada, em outro estudo com estagiários de Psicologia (Oliveira et al., 2019), como algo que promove o sentimento de que o estagiário é um profissional que faz parte da equipe. É possível afirmar que esse processo de comunicação promove o sentimento de engajamento no grupo e, portanto, inclusão.

Eu me sinto bastante incluída, tendo em vista que sou nova no estágio. As pessoas que trabalham mais diretamente comigo, elas sempre me explicaram tudo de tudo. Nada nunca foi barrado: "isso aqui você não pode participar." Pelo contrário, eu acho que sempre me deixaram a par de tudo (Dilma, estágio em projeto social).

As estagiárias se sentiam envolvidas e engajadas no grupo de trabalho quando outros membros do grupo incentivavam suas participações tanto na organização quanto na realização das atividades. No entanto, sentir-se incluída não é uma experiência psicológica que acontece apenas relacionada diretamente à execução do trabalho. As estagiárias relatam a importância de participar do grupo em outros momentos, como nos intervalos entre as atividades de trabalho, nas comemorações e nos registros fotográficos do grupo.

Além da questão da pouca experiência funcional, que marca o lugar de estagiária, a formação educacional (Psicologia) e as diferentes abordagens teóricas dentro da Psicologia também foram indicadas como fatores que interferem no processo de inclusão em contextos organizacionais, em que outras profissões da área de saúde ou psicólogas de outras abordagens teóricas têm um maior status e poder. A dinâmica do poder baseada em grupo, incluindo sistemas de dominação e subordinação, envolvendo profissões e ocupações, torna-se uma importante questão, visto que, além das interações interpessoais, os processos intergrupais 
precisam ser considerados para analisar a inclusão. O trabalho em diversidade tende a se concentrar nos processos envolvidos quando pessoas de diferentes grupos de identidade ou com diferentes atributos trabalham juntos em uma equipe ou organização (Ferdman \& Sagiv, 2012). No caso em estudo, as estagiárias trazem a questão da trabalhadora psicóloga inserida em uma equipe multiprofissional de saúde:

O espaço da Psicologia já não éo lugar mais valorizado, o de estagiária, em uma hierarquia do hospital, menos ainda. Nesse caso da sexta-feira, quando eu cheguei, as pessoas vieram conversar comigo sobre o que estava acontecendo e a gente discutiu o caso juntas. Para mim foi: "eu acho que eu fiz um trabalho legal aqui e construí um lugar nessa equipe, nesse espaço!" (Taís, estágio em hospital).

Teve uma situação chata com uma médica. Foi uma médica muito metida. E aí ela quis botar a gente pra fora. Ela estava no dia dessa visita. Ela levou uns três ou quatro estagiários de medicina e achava que eles sozinhos com ela que deveriam acompanhar [a usuária do serviço] (Aída, estágio em serviço de atenção à saúde mental).

Essa discussão remete a outro componente da experiência psicológica de inclusão, que trata de reconhecer e valorizar a diversidade. Reconhecimento da diversidade diz respeito a acreditar ter mais oportunidades de interagir e se comunicar de forma positiva e construtiva uns com os outros, sem preconceitos e sem recorrer a estereótipos, assim como diz respeito a um sentimento de interação justa (Ferdman et al., 2009). As narrativas, em geral, mostram dificuldades no reconhecimento da diversidade na relação com outros profissionais da área de saúde. As estagiárias expressaram que, em algumas situações, não sentiam que havia uma interação e comunicação justas e construtivas com trabalhadores da enfermagem e, especialmente, com médicos. Em alguns casos, não havia o reconhecimento do saber psicológico e, em outros, a estagiária não era reconhecida enquanto representante legítima desse saber. Incluir requer reavaliação coletiva sobre o que é apropriado e esperado, sobre as formas de trabalho e interação previamente aceitas como certas, de uma maneira que incorpore mais vozes e perspectivas, que não são familiares ou são desconfortáveis para os que já estavam no poder (Ferdman, 2014).
Eu estava atendendo uma paciente e um médico chegou e praticamente me ignorou, como se eu não existisse, como se eu fosse invisivel! E eu continuei! Ele esperou que eu levantasse e deixasse o espaço para ele. Ele olhou para mim e disse: "eu preciso atender!". E eu falei: "eu estou terminando! Assim que eu terminar eu chamo o senhor". Aí ele falou: "mas eu preciso atender agora". Eu falei: "mas eu tenho que concluir" (Leila, estágio em hospital).

A categoria reconhecimento da diversidade também apareceu na narrativa de uma estagiária, que problematizou a dificuldade da preceptora em reconhecer suas características pessoais em relação ao trabalho (ser estagiária e de Psicologia) e a atributos demográficos como raça e classe social. Questões que emergem da diversidade de identidade não podem ser vistas como monocausais ou baseadas em uma única forma de diferença, visto que as pessoas podem experimentar múltiplas formas de diferença que causam opressão. Para lidar com essa multiplicidade, utiliza-se como ferramenta a interseccionalidade, que indica que as pessoas são identificadas dentro de mais de uma categoria social e destaca que há várias e interligadas formas de opressão social, experimentadas por grupos historicamente marginalizados (Byrd, 2014). A narrativa citada, portanto, aponta que, para uma análise mais aprofundada do processo de inclusão, os atributos demográficos das estagiárias precisam ser considerados. Em um estudo brasileiro que investigou a inclusão entre trabalhadores negros nas organizações (D'Amario, 2009), os resultados indicaram que quanto maior a diversidade racial no grupo de trabalho, maior é a experiência de inclusão e que o comportamento inclusivo influencia na experiência de inclusão de forma mais intensa para pessoas negras que para pessoas não negras.

A gente se entende [duas estagiárias negras] enquanto ser estagiária, negra, no Sistema Único de Saúde. Com orientadoras que, geralmente, são brancas, como que se dá esse encontro? A gente sentia, por vezes, o que era ter uma preceptora branca. Havia um pouco de distância entre nós [estagiárias e preceptora]. Uma falta de entendimento de quem éramos nós: "quem são essas duas estagiárias que estão aqui hoje? Onde é que elas moram? O que elas fazem além do estágio? Elas moram sozinhas ou não? Quais são as demandas de suas 
vidas?". Então, era importante conhecer aquela pessoa que estava ali (Conceição, estágio em serviço de atenção à saúde mental).

Em suas narrativas, as estagiárias apontaram para a influência na tomada de decisão como outra importante dimensão que fazia com que elas se percebessem mais incluídas. Esse componente da experiência psicológica de inclusão pode ser descrito como o sentimento de influência sobre o processo de tomada de decisão e de que são pessoas valiosas e importantes no grupo de trabalho (Ferdman et al., 2009).

Ela [a preceptora, coordenadora do grupo] me convoca para eu raciocinar quais são os pacientes que a gente levaria para o grupo e quais não. Então, ela me coloca dessa forma: de eu poder decidir com quem a gente vai fazer o grupo. Em algum momento eu expresso a minha opinião e eu gosto de ouvir a opinião dela também. Às vezes, a gente compactua da mesma opinião e quando não compactua eu pergunto o porquê. E aí ela me explica e eu sempre aprendo muito (Fernanda, estágio em hospital).

Quando não é percebido o poder de influenciar nas decisões, as estagiárias se sentem menos incluídas, com menor participação e autonomia, tanto no processo de aprendizagem, como no processo de trabalho a ser desenvolvido por elas. Em outro estudo, estudantes de Psicologia se descrevem como "invisíveis", em algumas situações no estágio, visto que não eram convidados a participar de discussões e procedimentos inerentes a sua formação, além de, muitas vezes, serem ignorados no local de trabalho (Oliveira et al., 2019).

Eu não tenho tanta autonomia para decidir algumas conduções. Eu realmente não concordei em alguns momentos no que eu deveria fazer, mas tive que fazer. Essa ideia de exclusão acho que vem muito nesse momento de não concordar com o que deveria ser feito, mas ter que fazer ainda assim (Francisca, estágio em projeto social).

O sentimento de que se é valorizada também faz parte do processo de experiência psicológica de inclusão. Sentimento de valorização é o componente que envolve, além da percepção de que se é valorizado e que valoriza, o sentido de que um é importante para os outros no grupo, como pessoa e como membro de vários grupos de identidade social (Ferdman et al., 2009). A valorização da estagiária de Psicologia apareceu por parte de profissionais da Psicologia, outros trabalhadores da área de saúde (enfermeira, psiquiatra) e, também, por usuários do serviço de saúde. Nesse sentido, para além das relações interpessoais com membros do grupo de trabalho (intragrupais) e das relações entre os diferentes grupos no trabalho (intergrupais), os usuários do serviço de saúde podem se constituir como importantes atores para a construção da experiência psicológica de inclusão entre as estagiárias durante vivências de integração ensino-trabalho.

Teve um dia que a gente foi fazer uma visita no hospital, logo quando a gente começou a acompanhar o caso. A paciente estava dormindo. Aí eu tive a ideia da gente escrever um bilhete pra marcar presença. Fazer uma marcação temporal e dizer: "estamos aqui, vamos te acompanhar". Quando a gente foi embora, no carro do serviço, a psicóloga falou assim: "onde foi que você aprendeu isso?". E ela achou massa! Aí perguntou se a gente não poderia fazer meio que uma apresentação de conceitos, de teoria, que ela sentia muita falta. Pra mim, isso significou que ela estava observando o trabalho que a gente estava fazendo, admirando esse trabalho e queria aprender isso também. Aífoi nesse dia que eu pensei: "realmente, estamos fazendo parte de uma equipe!" (Elza, estágio em serviço de atenção à saúde mental).

\section{Reconhecimento e uso da voz como principais comportamentos inclusivos}

A experiência de inclusão é um estado psicológico e, mais provavelmente, estará presente em situações de trabalho em que haja comportamentos inclusivos por parte de membros do grupo de trabalho e de líderes (Ferdman et al., 2010). Dois componentes de comportamentos inclusivos se destacaram nas narrativas das estagiárias: reconhecer os outros; usar e dar voz. Esses comportamentos foram relatados pelas estagiárias como ações que promoveram um clima inclusivo durante o estágio. Cumprimentar e reconhecer outros indivíduos no trabalho, comportamento inclusivo denominado de reconhecer os outros (Ferdman et al., 2009), foi indicado pelas estagiárias como uma importante ação para promover a experiência psicológica de inclusão. 
Em função de as estagiárias serem recém-chegadas ao contexto de trabalho, os comportamentos dos novos colegas de trabalho, ao conversarem buscando informações sobre a pessoa e gravarem o nome da estagiária, foram pequenas ações que possibilitaram uma sensação de acolhimento. Além do reconhecimento da estagiária como pessoa, o reconhecimento enquanto uma profissional da Psicologia, por parte da preceptora e de outros trabalhadores da saúde, também foi um comportamento considerado inclusivo.

Ademais, cumprimentos sociais (a exemplo de "bom dia"), envolvendo outros trabalhadores do contexto de trabalho, foram apontados como uma ação de inclusão no grupo ou mesmo de exclusão, no caso da ausência. Esses comportamentos inclusivos foram realizados por trabalhadores de saúde em ocupações de menor status e a ausência de cumprimentos, por parte de enfermeiros e médicos. Elas relataram, também, seus próprios comportamentos inclusivos ao cumprimentarem outros trabalhadores da saúde, valorizando-os e, ao mesmo tempo, buscando sua valorização. Esse tipo de comportamento inclusivo, portanto, pode variar de um simples cumprimento a conversas com outras pessoas sobre suas atividades no fim de semana ou detalhes de suas vidas pessoais, bem como diálogos acerca de aspectos do trabalho do grupo (Ferdman et al., 2009) .

Na verdade as pessoas são muito acolhedoras. Não só com os assistidos, mas com a equipe também. Mesmo quando eu era muito nova, às vezes quando eu ia para a reunião geral, quando eu ainda não era conhecida, falavam, perguntavam: "você é estagiária nova? Você é de que curso? De que faculdade?". Então, sempre existia uma figura ou outra que, de alguma forma, fazia com que você se sentisse acolhida (Dandara, estágio em projeto social).

Nos primeiros boletins que eu acompanhei um médico, ele se apresentava: "eu sou Dr. Tal e essa daqui é psicóloga". Mas eu sou estudante! E isso ficava assim na minha cabeça: "ele já estava me validando como uma profissional!". Me senti de fato com muita voz e validada ali dentro daquele ambiente! (Paula, estágio em hospital).

Outro importante comportamento inclusivo, identificado nas narrativas, está relacionado ao uso da voz das estagiárias. Usar e dar voz refere-se ao comportamento de ter a oportunidade de falar e de se comunicar de forma clara, assim como de escutar os outros com atenção para ajudar a se sentirem ouvidos e compreendidos (Ferdman et al., 2009). As estagiárias se sentiam incluídas em situações em que falavam sobre suas impressões e reflexões a respeito dos casos que estavam acompanhando para preceptoras, orientadoras ou para equipes multiprofissionais. Além de as estagiárias adotarem o uso da fala, da mesma forma, observa-se nas narrativas o comportamento de dar voz às estagiárias, por parte de outros membros do grupo de trabalho, promovendo um clima inclusivo.

Quando o psiquiatra estava atendendo, às vezes ele deixava a oportunidade pra outras pessoas fazerem alguma intervenção, algum estudante fazer alguma intervenção. E no dia que eu estava atendendo uma pessoa e o psiquiatra perguntou: "qual a sua opinião enquanto psicólogo?". Eu achei aquilo como se tivesse importância! Eu gostei! Foi o dia em que eu me senti mais incluído, valorizado! (Luís, estágio em serviço de atenção à saúde mental).

Ademais, nas narrativas, ressalta-se que há profissões e ocupações que "têm uma voz mais poderosa". As entrevistadas falaram em uma "hierarquia de saber" que, por vezes, permite o uso da voz apenas a profissionais como médicos, quando se trata da área de saúde; a supervisores ou orientadores, no caso do processo de aprendizagem da profissão; e aos trabalhadores de saúde mais antigos, ao se considerar a estagiária como uma recém-chegada ao contexto de trabalho. O poder atribuído a esses membros do grupo de trabalho podelevar a um silêncio por parte das estagiárias, o que dificulta a comunicação de forma clara e direta e produz um sentimento de menor inclusão e questionamentos sobre o porquê de se calar. O sentimento de "não ter voz" e a falta de reconhecimento nos ambientes de trabalho foram relatados por estagiários de Psicologia, em outro estudo na Bahia, que percebiam elementos de vulnerabilidade na vivência do papel social de psicólogo (Oliveira et al., 2019).

Eu me sinto muito excluída quando eles vão tomar decisões sobre o caso e não chamam a gente para reunião. Vão os médicos, os residentes, os enfermeiros, todo mundo que maneja o caso, mas a gente não é chamada. Por que a gente não é con- 
sultada se é um procedimento adequado para ele? Eu acho que fica aí hierarquia de saberes (Lisiane, estágio em serviço de atenção à saúde mental).

Nas narrativas, os comportamentos inclusivos foram identificados como ações adotadas pelo indivíduo (estagiárias), pelos membros do grupo de trabalho (a exemplo de orientadoras, preceptoras, trabalhadores de saúde) e até mesmo pelos usuários dos serviços de saúde. Ao buscar reconhecer os outros indivíduos no trabalho e ao engajarem-se em comportamentos de voz, as estagiárias promovem a própria inclusão e a de sua profissão na área da saúde. Diante disso, contribuem para a ampliação dos horizontes da Psicologia em direção a novas territorialidades e serviços (Macedo \& Dimenstein, 2011).

Dentre os comportamentos interpessoais no contexto de trabalho, as pessoas que assumem lugares de liderança têm responsabilidades adicionais, como responsabilizar os outros por seu comportamento e estabelecer conexões apropriadas entre os objetivos organizacionais e a inclusão (Ferdman, 2014). No entanto, nos relatos das estagiárias, não foram identificadas políticas e procedimentos organizacionais voltados para a promoção de um clima inclusivo. Não foram apreendidos comportamentos inclusivos que, em geral, estão vinculados a políticas e práticas de gestão de diversidade, a exemplo de práticas que ajudem a lidar com conflitos e diferenças entre os membros do grupo e a aumentar a representação de pessoas de diferentes identidades no grupo de trabalho. Entende-se, portanto, que as organizações nas quais as estagiárias estavam inseridas não tinham ou não enfatizavam políticas e práticas voltadas para a inclusão dos trabalhadores.

Embora a heterogeneidade no mundo do trabalho seja uma realidade, as organizações no Brasil ainda não adotaram amplamente políticas de inclusão para atender as demandas relacionadas às diversidades (Torres et al., 2016). Ainda que se observe um crescente movimento de organizações no sentido de adotar programas de gestão da diversidade, há, em menor grau, programas de inclusão como parte de suas estratégias organizacionais (Torres \& Pérez-Nebra, 2014). Exige-se, no país, que haja uma cota reservada para trabalhadores pertencentes ao grupo de pessoas com deficiência e ao grupo de menores aprendizes (Torres et al., 2016). A ausência de outros dispositivos compulsórios pode estar associada ao reduzido número de políticas e práticas de inclusão, ao considerar a grande diversidade nas organizações. E mesmo para o grupo das pessoas com deficiência, apesar do grande avanço com a implementação da lei de cotas, muitas organizações não conseguem sequer cumprir com a demanda legislativa e lidam com grandes barreiras para inclusão, como acessibilidade precária e permanência de estereótipos e preconceitos (García, 2014).

Além disso, as políticas de diversidade podem estar associadas a resultados econômicos (quando a organização projeta uma imagem socialmente responsável, provocando a admiração do mercado e dos consumidores), o que não demonstra um interesse genuinamente social pelas diferenças e, na ausência de controle externo, funcionando mais como princípios do que como práticas socialmente comprometidas (Saraiva \& Irigaray, 2009). Dessa forma, o reduzido número de práticas organizacionais voltadas para a promoção de um clima inclusivo ou mesmo sua ausência pode ser entendida como uma característica que ultrapassa as organizações nas quais as estagiárias estavam inseridas.

\section{Inclusão no trabalho em diferentes níveis de análise}

Embora haja um maior foco no nível micro, da experiência individual e comportamento interpessoal cotidiano, destaca-se que a prática de inclusão aborda tanto esse nível, como o nível macro, que envolve as relações intergrupais, sistemas organizacionais e sociais complexos (Ferdman, 2014). O presente estudo enfatizou a inclusão em um nível micro, em especial, a experiência psicológica de inclusão das estagiárias de Psicologia, por meio de seus componentes, e os comportamentos inclusivos percebidos. Ainda nesse nível de análise, dentre os relatos das estagiárias, há a atribuição de características pessoais para compreender a experiência psicológica de inclusão.

A equipe sempre faz um movimento de incluir. Então, como eu sou uma pessoa muito calada, meio que fica aquele contraste, tipo: "você está incluída na equipe, mas você não está conversando, porque está todo mundo falando muito $e$ você está lá às vezes só". E, ao mesmo tempo em que eu me sinto muito incluída, quando eu penso nesse contraste, eu me sinto "um ponto fora do conjunto” (Sônia, estágio em projeto social). 
A experiência psicológica de inclusão também é facilitada e possibilitada pelas próprias atitudes e comportamentos do indivíduo (Ferdman, 2014). No entanto, embora tenham sido também citadas situações em que as estagiárias enfocam seus próprios comportamentos, a experiência psicológica de inclusão foi mais facilitada pelo comportamento interpessoal cotidiano atribuído, principalmente, à equipe de trabalho e aos profissionais de saúde (psicólogas, médicas, psiquiatras, enfermeiras, fisioterapeutas, assistentes sociais, psicanalistas). Em um nível macro, as relações intergrupais são relatadas, em especial, quando da tensão ou do acolhimento no encontro entre os saberes e fazeres psicológicos e os demais saberes e fazeres dos trabalhadores das equipes multiprofissionais de saúde.

A forma como os cursos de Psicologia estão organizados, muitas vezes, não possibilita o diálogo com outros saberes do âmbito da saúde, apontando para a necessidade do desenvolvimento de práticas que priorizem o diálogo e a atuação interdisciplinar, não só no contexto da Psicologia, mas também de outros cursos de formação superior (Oliveira et al., 2019). Apesar de os psicólogos estarem ampliando sua atuação, o que envolve o trabalho na área de saúde (segunda área de maior atuação), a clínica continua exercendo maior fascínio entre esses profissionais (Gondim, Bastos \& Peixoto, 2010). Ao escolherem o estágio em clínica, estudantes de Psicologia enfatizaram sua falta de disponibilidade para atuar em equipe com profissionais de outras áreas, o que sugere uma falta de articulação da Psicologia com outros campos de conhecimento (Oliveira et al., 2019). Esses achados apontam para os desafios das psicólogas no processo de inclusão em equipes multiprofissionais de saúde, que envolve não só a atuação no mundo do trabalho, como a formação para o trabalho em saúde.

Em suas narrativas sobre inclusão, as estagiárias mencionaram questões, em um nível macro, que estavam relacionadas aos sistemas organizacionais como a organização formadora (outras demandas de formação da universidade, que limitavam a participação em reuniões no local do estágio) e a organização vinculada ao estágio (condições de trabalho caracterizadas pela alta carga de trabalho dos profissionais).

A reunião da minha equipe acontece às quintas feiras, que é o dia que eu tenho disciplinas obrigatórias, que eu preciso para me formar. Então, eu não tenho como estar presente nessas reuniões. Por não participar das reuniões, acabava que algu- mas decisões eram tomadas e eu não estava presente. E a gente que estava no campo, junto com o paciente, a gente podia dar outro olhar (Daiane, estágio em Caps).

Para criar uma organização inclusiva não é suficiente trabalhar no nível individual: faz-se necessário que os sistemas organizacionais valorizem a diversidade e promovam processos inclusivos. No caso das Instituições de Ensino Superior do Brasil a diversidade e inclusão no trabalho representa um grande desafio, visto que, entre os docentes dessas instituições, há uma sub-representação de mulheres, pessoas negras e pessoas com deficiência (Costa, Oliveira, Meireles, \& Santana, 2019).

A inclusão aborda um nível ainda mais macro, que envolve sistemas sociais complexos, que também foram citados pelas estagiárias ao relatarem situações que envolviam privilégios relativos à raça/cor $\mathrm{e}$ à classe social, que facilitavam a experiência psicológica de inclusão. As experiências, comportamentos, políticas e práticas ocorrem no contexto de estruturas sociais mais amplas, que podem ou não apoiar a inclusão (Ferdman, 2014).

Então, você é uma mulher, que aparenta fazer parte de certa classe social, está num espaço, um hospital, que tem como predomínio o saber médico. Ali é um espaço de poder. Os profissionais que exercem esse poder, fisicamente, têm um estereótipo de brancos, que ocupam uma determinada classe social. Talvez, eu me adequar um pouco mais a esse estereótipo me facilite o diálogo, sem algum olhar, sem alguma dúvida sobre meu saber, algum questionamento (Clarice, estágio em hospital).

Dados empíricos apontam que mulheres pertencentes a grupos étnicos não brancos, se quiserem participar de redes influentes ou ter oportunidades de desenvolvimento e progresso na carreira, em organizações ocidentais brancas, são exigidas a se encaixarem na cultura existente, na qual há expectativas organizacionais em relação à demonstração de determinados comportamentos e à aparência pessoal (expressa através de roupas, penteados, uso de cosméticos e joias) (Kamenou \& Fearfull, 2006). O desenvolvimento de estudos sobre diversidade e inclusão nas organizações está atrelado ao reconhecimento das mudanças demográficas no mundo do trabalho, 
que envolve uma força de trabalho diversificada cada vez mais feminina, com pessoas negras e trabalhadores de diferentes lugares (Block \& Noumair, 2017).

Composta majoritariamente por uma força de trabalho feminina (Bastos, Gondim, \& Rodrigues, 2010), a categoria profissional vinculada à Psicologia precisa lidar com questões sociais que estão relacionadas às diferenças entre mulheres e homens no mundo do trabalho. Mulheres e homens com mesmo nível educacional tendem a ocupar cargos com exigências diferentes, visto que a forma como as organizações investem em habilidades no local de trabalho por meio da oferta de treinamentos podem representar um "teto de vidro" que as mulheres encontram imediatamente após a formatura (Boye \& Grönlund, 2018). Esse também pode ser um grande desafio às psicólogas, em especial, às recém-formadas, na busca por inclusão em equipes multiprofissionais de saúde e em espaços de liderança desses grupos.

Embora o foco tenha sido nos atributos "formação educacional" (psicólogas) e "experiência funcional" (estagiárias), o presente trabalho reconhece que existem inúmeras fontes de diversidade nos contextos de trabalho e que os grupos de trabalho são diversos em muitos aspectos simultaneamente. Os atributos de diversidade se misturam criando ambientes complexos, nos quais um membro do grupo interno em um aspecto (por exemplo, profissão) é um membro do grupo externo em outro aspecto (por exemplo, gênero). Pesquisadores e profissionais estão cientes dessas múltiplas fontes de diversidade, embora seja difícil, e talvez mesmo impossível, considerar todas elas simultaneamente (Ferdman \& Sagiv, 2012).

Apesar de haver dificuldades em considerar essas múltiplas fontes de diversidade nos estudos, também denominadas de múltiplas identidades, torna-se fundamental reconhecer sua importância. Estudiosos argumentam que três dimensões sociais fundamentais se combinam para fornecer uma base para a percepção social: raça, gênero e classe social (Kang \& Bodenhausen, 2015). Esses sistemas de diferença, uma vez estabelecidos, aparecem nos significados e identidades que as pessoas constroem como indivíduos, nos padrões de interação entre pessoas, na distribuição de recursos nas sociedades, nas estruturas hierárquicas e, também, nas práticas de trabalho nas organizações (Ely \& Padavic, 2007).

Em algumas situações, as estagiárias afirmaram que, ainda que não tivessem se sentido incluídas, não podiam dizer que se sentiram excluídas. Embora inclusão e exclusão possam parecer opostas - porque inclusão implica em se sentir ouvida, valorizada e respeitada, enquanto exclusão implica em não se sentir ouvida, valorizada e respeitada -, as estagiárias apontam para a natureza complexa dos fenômenos ao diferenciarem entre não se sentir incluída do sentimento de exclusão. Essa diferenciação remete para a necessidade de refletir sobre as possíveis intensidades no processo de inclusão, que podem ter como um polo a exclusão, assim como sobre a possibilidade de compreender a inclusão e a exclusão como fenômenos distintos. Dessa forma, torna-se importante questionar se esses conceitos devem ser integrados, tratados de forma simultânea ou de forma paralela e independente.

\section{Considerações finais}

O desenvolvimento deste estudo, que buscou compreender as experiências psicológicas de inclusão a partir das vozes das estagiárias de Psicologia, possibilitou a produção de conhecimentos que caracterizam o processo de inclusão em contextos de trabalho. Entende-se que esses conhecimentos podem promover importantes discussões e, assim, fundamentar a elaboração de políticas e práticas organizacionais mais inclusivas para lidar com uma força de trabalho diversa. Essa diversidade abrange, além dos atributos relacionados aos grupos de identidades sociais mais estudados, os atributos de experiência no trabalho e categoria profissional.

Os resultados do estudo afirmaram a importância dos estágios curriculares como dispositivos de inclusão de trabalhadores no mundo do trabalho, visto que a condição de estagiária constituiu uma dimensão central de diversidade nesse processo de inclusão. As narrativas produzidas pelas estagiárias apresentaram situações vivenciadas em contextos de trabalho, que possibilitaram ampliar a compreensão de como pode ser construída a experiência psicológica de inclusão. Além disso, foram enfatizados comportamentos inclusivos que envolveram, por parte das estagiárias, falar e fazer contribuições para a equipe multiprofissional de saúde e, por parte da equipe, fornecer oportunidades para que as estagiárias o fizessem, bem como mostrar que suas contribuições eram valorizadas.

Destaca-se, portanto, que a inclusão é um processo multinível, pois envolve os níveis: individual, com as experiências psicológicas das estagiárias; interpessoal, por meio dos comportamentos cotidianos das pessoas com as quais as estagiárias se relacionavam no 
trabalho; intragrupal, nas relações estabelecidas dentro dos grupos aos quais as estagiárias pertenciam, a exemplo da equipe multiprofissional de saúde; intergrupal, por meio das relações entre os diferentes grupos, como aqueles que representavam as diferentes categorias profissionais na saúde.

As estagiárias falam de um lugar de recém-chegadas como trabalhadoras, visto que estão iniciando suas experiências de trabalho na equipe, assim como de recém-chegadas como representantes da Psicologia, já que essa nem sempre é percebida como uma profissão da área da saúde. Em geral, há expectativas de que recém-chegadas se adaptem ao modo como as coisas já são feitas nas organizações de saúde. Coube às estagiárias, como foi possível apreender de suas narrativas, diante dos saberes da Psicologia, negociarem os fazeres já instituídos nas equipes de saúde. Essa negociação não parece simples, pois envolve buscar um equilíbrio entre ser incluída na equipe multiprofissional de saúde (sendo aceita como uma delas) e, ao mesmo tempo, se destacar dentro da equipe pelas especificidades da identidade profissional (marcando as diferenças em relação aos demais membros). Para produzir os benefícios potenciais de uma equipe de saúde não é suficiente incorporar a diversidade de profissões, dado que os resultados do trabalho dependerão de como essa diversidade é tratada pelos membros do grupo e pelo ambiente organizacional.

Ademais, níveis mais macro como o organizacional (envolvendo as organizações de saúde e as educacionais) e os sistemas sociais também devem ser investigados para uma análise mais complexa e aprofundada do processo de inclusão. Essa ampliação do foco de análise pode levar a reflexões sobre a adoção de políticas e práticas voltadas para a produção de comportamentos inclusivos organizacionais, como reforçar a representação (aumentando a presença de pessoas de diferentes identidades sociais no grupo de trabalho em todos os níveis da organização) e criar um ambiente de segurança (favorecendo o compartilhamento de recursos, ideias e perspectivas). Diante disso, estudos sobre a inclusão no trabalho precisam considerar sua característica multinível.

Visto que o tempo foi enfatizado pelas estagiárias como um fator importante para a experiência psicológica de inclusão, entende-se como necessária uma perspectiva que reconheça a dinâmica temporal inerente ao processo de inclusão e as maneiras pelas quais as pessoas podem alternar entre inclusão e exclusão ao longo do tempo. Ademais, as experiências psicológicas de inclusão podem diferir em distintos contextos de trabalho. Nesse sentido, tornam-se importantes abordagens longitudinais e que considerem as questões contextuais para uma compreensão mais sutil dos processos envolvidos na experiência psicológica de inclusão.

Em contextos de integração ensino-trabalho, como os estágios, as estudantes reconhecem potencialidades e limitações do exercício profissional. Engajar-se no grupo de trabalho, ter influência nas tomadas de decisões, ser valorizada, são desafios apresentados às profissionais de Psicologia em equipes multiprofissionais de saúde, em especial, às recém-chegadas a esse contexto de trabalho. Esse desafio, no entanto, não é apenas individual: envolve também as equipes de trabalho, as organizações de saúde e as universidades, como fomentadoras de espaços privilegiados de inclusão para vivências mais potentes de integração ensino-trabalho.

\section{Referências}

Bastos, A. V. B., Gondim, S. M. G., \& Rodrigues, A. C. de A. (2010). Uma categoria profissional em expansão: Quantos somos e onde estamos? In A. V. B. Bastos \& S. M. G. Gondim (Orgs.), O trabalho do psicólogo no Brasil (pp. 32-44). Artmed.

Block, C. J., \& Noumair, D. A. (2017). Understanding diversity dynamics in systems: Social equality as an organization change issue. TheJournalofApplied BehavioralScience, 53(2),150-155.https://doi.org/10.1177/0021886317703250

Boye, K., \& Grönlund, A. (2018). Workplace skill investments - An early career glass ceiling? Job complexity and wages among young professionals in Sweden. Work, Employment and Society, 32(2), 368-386. https://doi.org/ $10.1177 / 0950017017744514$

Byrd, M. Y. (2014). Diversity issues: Exploring "critical" through multiple lenses. Advances in Developing Human Resources, 16(4), 515-528. https://doi.org/10.1177/1523422314544297

Costa, F. M., Oliveira, R. P., Meireles, E. C. A., \& Santana, L. A. A. (2019). Diversidade entre docentes das Instituições de Educação Superior brasileiras. Educação, Psicologia e Interfaces, 3(4), 67-82. https://doi.org/10.37444/ issn-2594-5343.v3i4.150 
D’Amario, E. Q. (2009). Comportamento inclusivo e experiência de inclusão: Um estudo sobre trabalhadores negros [Dissertação de mestrado, Universidade Presbiteriana Mackenzie].

Ely, R., \& Padavic, I. (2007). A feminist analysis of organizational research on sex differences. Academy of Management Review, 32(4), 1121-1143.

Ferdman, B. M. (2014). The practice of inclusion in diverse organizations: Toward a systemic and inclusive framework. In B. M. Ferdman \& B. R. Deane (Orgs.), Diversity at work: The practice of inclusion (pp. 3-54). Jossey-Bass.

Ferdman, B. M. (2017). Paradoxes of inclusion: Understanding and managing the tensions of diversity and multiculturalism. The Journal of Applied Behavioral Science, 53(2), 235-263. https://doi.org/ $10.1177 / 0021886317702608$

Ferdman, B. M., Avigdor, A., Braun, D., Konkin, J., \& Kuzmycz, D. (2010). Collective experience of inclusion, diversity, and performance in work groups. RAM. Revista de Administração Mackenzie, 11(3), 6-26. https://doi.org/ $10.1590 /$ S1678-69712010000300003

Ferdman, B. M, Barrera, V., Allen, A. A., \& Vuong, V. (2009). Inclusive behavior and the experience of inclusion. In B. G. Chung (Org.), Inclusion in Organizations: Measures, HR Practices, and Climate [Symposium]. Annual Meeting of the Academy of Management, Chicago.

Ferdman, B. M., \& Deane, B. R. (2014). Preface. In B. M. Ferdman \& B. R. Deane (Orgs.), Diversity at work: The practice of inclusion (pp. xxi-xxxii). Jossey-Bass.

Ferdman, B. M., \& Sagiv, L. (2012). Diversity in organizations and cross-cultural work psychology: What if they were more connected? Industrial and Organizational Psychology: Perspectives on Science and Practice, 5(3), 323-345. https://doi.org/10.1111/j.1754-9434.2012.01455.x

García, V. G. (2014). Panorama da inclusão das pessoas com deficiência no mercado de trabalho no Brasil. Trabalho, Educação e Saúde, 12(1), 165-187. https://doi.org/10.1590/S1981-77462014000100010

Gibbs, G. (2009). Análise de biografias e narrativas. In Análise de dados qualitativos (pp. 79-96). Artmed.

Gondim, S. M. G., Bastos, A. V. B., \& Peixoto, L. S. A. (2010). Áreas de atuação, atividades e abordagens teóricas do psicólogo brasileiro. In A. V. B. Bastos \& S. M. G. Gondim (Orgs.), O trabalho do psicólogo no Brasil (pp. 174-199). Artmed.

Hanashiro, D. M. M., Torres, C. V., Ferdman, B. M., \& D’Amario, E. Q. (2011). Medindo inclusão no ambiente organizacional: Uma visão "Emic" da Escala de Comportamento Inclusivo [Trabalho apresentado]. XXXV Encontro Anual da Associação Nacional de Pós-graduação e Pesquisa em Administração, Rio de Janeiro.

Jovchelovitch, S., \& Bauer, M.W. (2015) Entrevista narrativa. In M.W. Bauer \& G. Gaskell (Eds.), Pesquisa qualitativa com texto, imagem e som: Um manual prático (pp. 90-113). Vozes.

Kamenou, N., \& Fearfull, A. (2006). Ethnic minority women: A lost voice in HRM. Human Resource Management Journal, 16(2), 154-172. https://doi.org/10.1111/j.1748-8583.2006.00010.x

Kang, S. K., \& Bodenhausen, G. V. (2015). Multiple identities in social perception and interaction: Challenges and opportunities. Annual Review of Psychology, 66, 547-574. https://doi.org/10.1146/annurev-psych-010814-015025

Macedo, J. P., \& Dimenstein, M. (2011). Expansão e interiorização da Psicologia: Reorganização dos saberes e poderes na atualidade. Psicologia: Ciência e Profissão, 31(2), 296-313. https://doi.org/10.1590/S1414-98932011000200008

Oliveira, R. de O., Costa, F. M., Santos, G. S. dos, Barreto, M. C. M. dos Santos, Andrade, M. S. de, \& Gomes, M. M. de S. (2019). "Um ensaio da vida profissional": Significados do estágio em Psicologia entre estagiários da UFRB. In S. Aires \& S. Kuratani (Orgs.), O serviço de Psicologia da universidade (pp. 163-183). UFRB.

Rosa, A. R. (2014). Relações raciais e estudos organizacionais no Brasil. Revista de Administração Contemporânea, 18(3), 240-260. http://doi.org/10.1590/1982-7849rac20141085

Saraiva, L. A. S., \& Irigaray, H. A. dos R. (2009). Políticas de diversidade nas organizações: Uma questão de discurso? Revista de Administração de Empresas, 49(3), 337-348. https://doi.org/10.1590/S0034-75902009000300008

Torres, C. V., França, L. H. F. P., Oliveira, A., \& Presotti, L. (2016). Diagnóstico de diversidade cultural e inclusão nas organizações. In H. Mendonça, M. C. Ferreira \& E. R. Neiva (Orgs.), Análise e diagnóstico organizacional: Teoria e prática (pp. 195-228). Vetor. 
Torres, C. V., \& Pérez-Nebra, A., R. (2014). Diversidade e inclusão nas organizações. In J. C. Zanelli, J. E. BorgesAndrade \& A. V. B. Bastos (Orgs), Psicologia, organizações e trabalho no Brasil (pp. 526-546). Artmed.

Van Knippenberg, D., \& Schippers, M. C. (2007). Work group diversity. Annual Review of Psychology, 58, 515-541. https://doi.org/10.1146/annurev.psych.58.110405.085546

\section{Fabíola Marinho Costa}

Docente na Universidade Federal do Recôncavo da Bahia (UFRB), Santo Antônio de Jesus - BA, Brasil. E-mail: fabiola@ufrb.edu.br

(1) https:// orcid.org/0000-0001-6077-7688

\section{Roberval Passos de Oliveira}

Docente na Universidade Federal do Recôncavo da Bahia (UFRB), Santo Antônio de Jesus - BA, Brasil.

E-mail: robervaloliveira@ufrb.edu.br

(1) https://orcid.org/0000-0002-0874-5344

\section{Antonio Virgílio Bittencourt Bastos}

Docente na Universidade Federal da Bahia (UFBA), Salvador - BA, Brasil.

E-mail: antoniovirgiliobastos@gmail.com

(1) https://orcid.org/0000-0002-1322-5749

Endereço para envio de correspondência:

Centro de Ciências da Saúde, Universidade Federal do Recôncavo da Bahia. Avenida Carlos Amaral, 1015, Cajueiro. CEP: 44430-622. Santo Antônio de Jesus - Bahia. Brasil.

Recebido 30/03/2020

Aceito 02/03/2021

Received $03 / 30 / 2020$

Approved 03/02/2021

Recibido $30 / 03 / 2020$

Aceptado 02/03/2021

Como citar: Costa, F. M., Oliveira, R. P. de, \& Bastos, A. V. B. (2022). Experiência psicológica de inclusão entre estagiárias de Psicologia em equipes multiprofissionais. Psicologia: Ciência e Profissão, 42, 1-15. https://doi.org/ $10.1590 / 1982-3703003235842$

How to cite: Costa, F. M., Oliveira, R. P. de, \& Bastos, A. V. B. Psychologic experience of inclusion between psychology interns in multiprofessional teams. Psicologia: Ciência e Profissão, 42, 1-15. https://doi.org/ $10.1590 / 1982-3703003235842$

Cómo citar: Costa, F. M., Oliveira, R. P. de, \& Bastos, A. V. B. Experiencia psicológica de inclusión entre pasantes de Psicología en equipos multiprofesionales. Psicologia: Ciência e Profissão, 42, 1-15. https://doi.org/ $10.1590 / 1982-3703003235842$ 